\title{
High levels of lipoprotein(a) are associated with a lower prevalence of diabetes with advancing age: Results of a cross-sectional epidemiological survey in Gran Canaria, Spain
}

\author{
Mauro Boronat ${ }^{1,2^{*}}$, Pedro Saavedra ${ }^{3}$, Nuria Pérez-Martín', María J López-Madrazo ${ }^{1}$, Carlos Rodríguez-Pérez
} and Francisco J Nóvoa ${ }^{1,2}$

\begin{abstract}
Background: Recent data suggest that concentrations of lipoprotein(a) $[L p(a)]$ may be inversely associated with the risk of diabetes. This study analyzed the relationships between $L p(a)$ and both diabetes and insulin resistance in an adult cohort from the island of Gran Canaria, Spain.

Methods: Lp(a), homeostasis model assessment for insulin resistance (HOMA-IR) and conventional risk factors for diabetes were assessed in a sample of 1,030 adult individuals participating in a cross-sectional population-based epidemiological survey in the city of Telde. Diabetes was defined according to the WHO 1999 criteria, or as a previous diagnosis of diabetes. To identify patients at risk for diabetes, an Lp(a) cutoff level of $46 \mathrm{mg} / \mathrm{dl}$ was selected previously using classification and regression tree analysis. A multivariate logistic regression model with $L_{2}{ }^{-}$ regularization was used to assess the independent effect of $L p(a)$ on diabetes and its interactions with variables traditionally linked to the disease. Additionally, to investigate the effect of $L p(a)$ on insulin resistance, a parametric model was developed to describe the relationship between age and HOMA-IR values in subjects with levels of Lp (a) $\leq 46$ or $>46 \mathrm{mg} / \mathrm{dl}$.
\end{abstract}

Results: Along with variables known to be associated with diabetes, including age, mean blood pressure, serum triglycerides, and an interaction term between age and low HDL cholesterol, the logistic model identified a significant inverse association for diabetes and the interaction term between age and $L p(a)$ levels $>46 \mathrm{mg} / \mathrm{dl}$. According to the proposed parametric model, HOMA-IR was significantly lower in subjects of all ages who had Lp (a) levels $>46 \mathrm{mg} / \mathrm{dl}$.

Conclusions: These results suggest that the age-related increase in the probability of having diabetes is significantly lower in subjects with $L p(a)$ levels $>46 \mathrm{mg} / \mathrm{dl}$. This could be explained in part by a lower insulin resistance in this subset of the population.

Keywords: Lipoprotein(a), Diabetes, Insulin resistance, HOMA-IR, Age

\footnotetext{
*Correspondence: mborcor@ono.com

${ }^{1}$ Section of Endocrinology and Nutrition, Hospital Universitario Insular, Avda.

Marítima del Sur, s/n., 35016, Las Palmas de Gran Canaria, Spain

${ }^{2}$ Department of Medical and Surgical Sciences, University of Las Palmas de

Gran Canaria, Las Palmas de Gran Canaria, Spain

Full list of author information is available at the end of the article
} 


\section{Background}

Lipoprotein(a) $[\mathrm{Lp}(\mathrm{a})]$ is a plasma lipoprotein consisting of a LDL-like particle with a molecule of apolipoprotein B100 covalently linked to a very large additional glycoprotein known as apolipoprotein(a). Elevated Lp(a) levels constitute an independent risk factor for cardiovascular disease in the general population [1].

$\mathrm{Lp}$ (a) concentrations show considerable variation in healthy individuals, and are controlled mainly by genetics $[2,3]$. Nearly $90 \%$ of $L p(a)$ variation depends on biosynthesis of the distinctive apolipoprotein(a) protein, which is encoded by the LPA locus [2]. Many classic and novel risk factors have been investigated to determine whether they explain the higher risk of cardiovascular disease among people with diabetes [4-6]. In particular, several studies have examined the possibility that type 2 diabetes could influence $\mathrm{Lp}(\mathrm{a})$ concentrations. The results of several small case-control studies have been controversial. Subjects with diabetes have been found to have higher [7,8], similar [9] or lower levels of $\mathrm{Lp}(\mathrm{a})$ [10] than controls without diabetes. Using a different approach to analyze the interaction between $\mathrm{LP}(\mathrm{a})$ and diabetes, a more recent prospective study [11] of healthy US women aged 45 years or older (Women's Health Study [WHS]) revealed an inverse association between $\mathrm{Lp}(\mathrm{a})$ and the risk of incident type 2 diabetes. The authors replicated their findings in a Danish populationbased cohort (Copenhagen City Heart Study [CCHS]) with prevalent diabetes. These findings suggest that Lp (a) has opposite effects on the risks of cardiovascular disease and diabetes, increasing the former and decreasing the latter.

The aim of the present study was to examine the relationships between $\mathrm{Lp}$ (a) concentrations and both diabetes and insulin resistance in a cohort of adult subjects from the general population of the Canary Islands, Spain.

\section{Research design and methods}

\section{Subjects and measurements}

The study population was composed of 1,030 adult subjects ( $\geq 30$ years-old) who were participating in a crosssectional population-based study in Telde, a city located on the island of Gran Canaria, Canary Islands, Spain. The design of this survey was described previously [12] Participants were selected randomly from the local census. All subjects provided written informed consent for participation in the study, which was approved by the ethics committee of the Hospital Universitario Insular of Las Palmas.

Subjects filled out a survey questionnaire, underwent physical examination, gave fasting blood samples, and, except for those with known diabetes, underwent a 75-g standardized oral glucose tolerance test (OGTT).
Diabetes was defined as a previous diagnosis of diabetes with ongoing treatment with oral agents and/or insulin or was defined using the $1999 \mathrm{WHO}$ diagnostic criteria (fasting plasma glucose $\geq 7.0 \mathrm{mmol} / \mathrm{l}$ and/or 2 $\mathrm{h}$ plasma glucose $\geq 11.1 \mathrm{mmol} / \mathrm{l}$ ) [13]. A total of 128 subjects were classified as having type 2 diabetes, while 902 did not have diabetes. The homeostasis model assessment for insulin resistance (HOMA-IR) was calculated according to the formula HOMA-IR = fasting insulin $(\mathrm{mU} / \mathrm{l}) \times$ fasting plasma glucose $(\mathrm{mmol} / \mathrm{l}) / 22.5$ [14]. Plasma insulin was measured by a chemiluminescent assay (Elecsys 2010; Roche Diagnostics, Basel, Switzerland) and Lp(a) was measured by nephelometry, using a Dimension RxL autoanalyzer (Dade-Behring, Liederbach, Germany).

\section{Statistical analysis}

A classification and regression tree (CART) analysis selected an Lp(a) cutoff level of $46 \mathrm{mg} / \mathrm{dl}$ for the identification of patients at risk for diabetes. CART is a nonparametric validated statistical procedure in which classification and regression trees are constructed to predict an outcome variable from among a large number of variables and their interactions. Explanatory variables can be categorical and/or numeric [15]. To analyze the eventual effect of $\mathrm{Lp}(\mathrm{a})$ on diabetes, a multivariate logistic analysis was carried out. Variables entered into the model were $\mathrm{Lp}$ (a) (with categories $>46$ and $\leq 46 \mathrm{mg} / \mathrm{dl}$ ), age, sex, presence of abdominal obesity (defined as a waist circumference $\geq 102 \mathrm{~cm}$ for men and $\geq 88 \mathrm{~cm}$ for women) [16], blood pressure (entered as mean arterial pressure [MAP]), low levels of HDL cholesterol (HDL cholesterol $<40 \mathrm{mg} / \mathrm{dl}$ for men and $<50 \mathrm{mg} / \mathrm{dl}$ for women) [16], serum triglycerides (logarithmic scale), LDL cholesterol, and self-reported use of statins. Levels of triglycerides were logarithmically transformed to reduce skewness. All variables in the groups with or without diabetes were checked for outliers. In order to explore all possible interactions, we used a variant of logistic regression with $\mathrm{L}_{2}$-regularization to fit models with interactions [17]. A forward selection procedure of variables and their interactions was performed based on the Akaike's information criterion. The model was fitted using the iteratively reweighted ridge regressions algorithm. Odd-ratios of interest were computed from the obtained model along with estimated 95\% confidence intervals.

To further explore glucose homeostasis based on levels of $\mathrm{Lp}(\mathrm{a})$, the relationship between age and HOMA-IR values (in log scale) was modeled as follows:

$$
\begin{aligned}
\mathrm{E}[\log (\mathrm{HOMA}-\mathrm{IR}) \mid \mathrm{Lp}(\mathrm{a})] & =\theta+\beta \times \text { age }+\gamma \\
& \times \mathrm{Lp}(\mathrm{a})_{46} \times \mathrm{age}^{2} .
\end{aligned}
$$


Table 1 Characteristics of the population according to the presence or absence of diabetes

\begin{tabular}{|c|c|c|c|c|}
\hline & Total $(\mathrm{N}=1030)$ & Diabetes $(\mathrm{N}=128)$ & No diabetes $(\mathrm{N}=902)$ & $p$-value \\
\hline Age (years) & $48.0 \pm 11.9$ & $58.9 \pm 10.4$ & $46.5 \pm 11.3$ & $<0.001$ \\
\hline Male / Female (\%) & $43.5 / 56.5$ & $57.8 / 42.2$ & $41.5 / 58.5$ & $<0.001$ \\
\hline BMI $\left(\mathrm{kg} / \mathrm{m}^{2}\right)$ & $28.2 \pm 5.0$ & $31.0 \pm 5.4$ & $27.8 \pm 4.8$ & $<0.001$ \\
\hline Waist (cm) & $97 \pm 14$ & $107 \pm 12$ & $95 \pm 13$ & $<0.001$ \\
\hline Abdominal obesity (\%) & 57.4 & 83.6 & 53.7 & $<0.001$ \\
\hline Systolic blood pressure (mmHg) & $119 \pm 16$ & $134 \pm 16$ & $117 \pm 15$ & $<0.001$ \\
\hline Diastolic blood pressure (mmHg) & $73 \pm 10$ & $79 \pm 10$ & $72 \pm 10$ & $<0.001$ \\
\hline Smoking (\%) & 24.2 & 11.7 & 25.9 & $<0.001$ \\
\hline Current use of statins (\%) & 14.8 & 29.7 & 12.6 & $<0.001$ \\
\hline Total cholesterol (mg/dl) & $212 \pm 38$ & $217 \pm 44$ & $212 \pm 37$ & 0.170 \\
\hline LDL cholesterol (mg/dl) & $131(112-154)$ & $134(106-157)$ & $131(112-154)$ & 0.833 \\
\hline Triglycerides (mg/dl) & $103(74-148)$ & $132(102-190)$ & $100(71-142)$ & $<0.001$ \\
\hline HDL cholesterol (mg/dl) & $54 \pm 12$ & $50 \pm 13$ & $55 \pm 12$ & $<0.001$ \\
\hline Low HDL-cholesterol (\%) & 21.4 & 35.2 & 19.4 & $<0.001$ \\
\hline $\operatorname{Lp}(\mathrm{a})(\mathrm{mg} / \mathrm{dl})$ & $13.8(5.8-32)$ & $13.1(4.8-29.3)$ & $13.8(6.0-33.1)$ & 0.354 \\
\hline Lp(a) >46 mg/dl (\%) & 13.7 & 9.4 & 14.3 & 0.129 \\
\hline Fasting plasma glucose (mg/dl) & $91(82-101)$ & $138(116-177)$ & $88(82-97)$ & $<0.001$ \\
\hline $\mathrm{HbA}_{1 c}(\%)$ & $5.4(5.1-5.7)$ & $6.8(6.0-8.2)$ & $5.3(5.1-5.6)$ & $<0.001$ \\
\hline HOMA-IR & $1.6(1.0-2.7)$ & $4.0(2.7-6.6)$ & $1.5(1.0-2.3)$ & $<0.001$ \\
\hline Serum creatinine (mg/dl) & $0.8(0.7-0.9)$ & $0.8(0.7-1.0)$ & $0.8(0.7-0.9)$ & 0.001 \\
\hline
\end{tabular}

Results are expressed as mean \pm SD or median (interquartile range) for variables with skewed distribution.

In this parametric equation, $\mathrm{Lp}(\mathrm{a})_{46}$ has a value of 1 if $\mathrm{Lp}(\mathrm{a})$ is greater than $46 \mathrm{mg} / \mathrm{dl}$ and a value of 0 if $\mathrm{Lp}(\mathrm{a})$ is equal to or less than $46 \mathrm{mg} / \mathrm{dl}$. All statistical analyses were performed using the R-package stepPlr.

\section{Results}

Table 1 shows the demographic characteristics of the survey population. The median level of $\mathrm{Lp}$ (a) was 14.0 (interquartile range: $5.1-29.8) \mathrm{mg} / \mathrm{dl}$ in subjects with diabetes and $13.8(6.0-33.0) \mathrm{mg} / \mathrm{dl}$ in subjects without diabetes $(p=0.35)$. There was no significant difference in the percentage of individuals with $\mathrm{Lp}(\mathrm{a})>46 \mathrm{mg} / \mathrm{dl}$ between the groups with or without diabetes $(9.4 \%$ vs. $14.3 \% ; p=0.13$ ). A significantly higher percentage of subjects with diabetes reported taking statins compared to subjects without diabetes $(29.7 \%$ vs. $14.8 \%$; $p<0.001)$.

Subjects with $\mathrm{Lp}(\mathrm{a})>46 \mathrm{mg} / \mathrm{dl}$ were older than those with $\mathrm{Lp}(\mathrm{a}) \leq 46 \mathrm{mg} / \mathrm{dl}(50.0 \pm 11.9$ years vs. $47.7 \pm$ 11.9 years, $p=0.034)$. The gender distribution, the percentage of postmenopausal women, and the percentage of women on hormone replacement therapy was not significantly different between groups with levels of $\mathrm{Lp}(\mathrm{a})$ $\leq 46$ vs. $>46 \mathrm{mg} / \mathrm{dl}$.

As expected, most of the variables traditionally linked to diabetes were independently associated with the outcome in the multivariate logistic regression model: age $(p<0.001), \quad$ MAP $(p<0.001), \quad$ serum triglycerides $(p=0.001)$, and the interaction term between age and low HDL cholesterol $(p=0.007)$. In addition, there was a significant inverse association between diabetes and the interaction term age $\times \mathrm{Lp}(\mathrm{a})>46 \mathrm{mg} / \mathrm{dl}(p=0.048)$. As both HDL cholesterol and $\mathrm{Lp}(\mathrm{a})>46 \mathrm{mg} / \mathrm{dl}$ showed significant interactions with age, the association between age and diabetes was different in each of the four cohorts determined by the two factors (Table 2). Figure 1 shows the probability of diabetes according to age and

Table 2 Results of multivariate logistic regression analysis

\begin{tabular}{|c|c|c|}
\hline Factor & Cohort & OR $(95 \% \mathrm{Cl})$ \\
\hline \multirow[t]{4}{*}{ Age (per year) } & $\begin{array}{l}\text { Lp(a) } \leq 46 \mathrm{mg} / \mathrm{dl} / \text { Normal } \\
\text { HDL-C }\end{array}$ & $1.075(1.055 ; 1.095)$ \\
\hline & $\begin{array}{l}\mathrm{Lp}(\mathrm{a})>46 \mathrm{mg} / \mathrm{dl} / \text { Normal } \\
\text { HDL-C }\end{array}$ & $1.062(1.039 ; 1.085)$ \\
\hline & $\begin{array}{l}\mathrm{Lp}(\mathrm{a}) \leq 46 \mathrm{mg} / \mathrm{dl} / \mathrm{Low} \\
\mathrm{HDL}-\mathrm{C}\end{array}$ & $1.087(1.066 ; 1.109)$ \\
\hline & $\begin{array}{l}\mathrm{Lp}(\mathrm{a})>46 \mathrm{mg} / \mathrm{dl} / \mathrm{Low} \\
\mathrm{HDL}-\mathrm{C}\end{array}$ & $1.074(1.050 ; 1.098)$ \\
\hline Mean arterial pressure & All subjects & $1.060(1.039 ; 1.081)$ \\
\hline Log-Triglycerides & All subjects & $2.317(1.417 ; 3.787)$ \\
\hline
\end{tabular}

HDL-C: HDL cholesterol. 


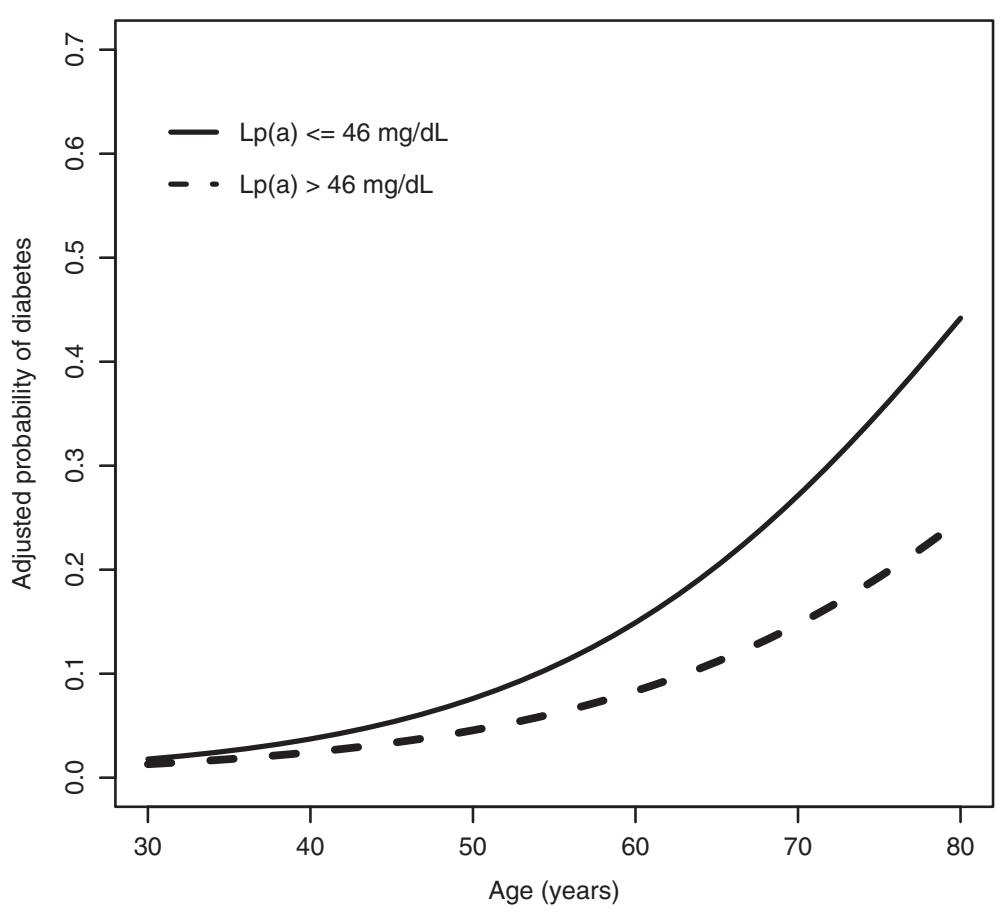

Figure 1 Adjusted probability of diabetes mellitus according to age and status of $L p(a)$ status.

Lp(a) level, adjusting for triglycerides, MAP, and HDL cholesterol.

Figure 2 shows the adjustment of log (HOMA-IR) according to our proposed parametric model for subjects with levels of $\mathrm{Lp}(\mathrm{a})>46$ and for subjects with levels of $\mathrm{Lp}(\mathrm{a}) \leq 46 \mathrm{mg} / \mathrm{dl}$. Predicted values of $\log$ (HOMA-IR) were higher in subjects with $\mathrm{Lp}$ (a) levels $\leq 46 \mathrm{mg} / \mathrm{dl}$. The differences increased with the age, although the lower

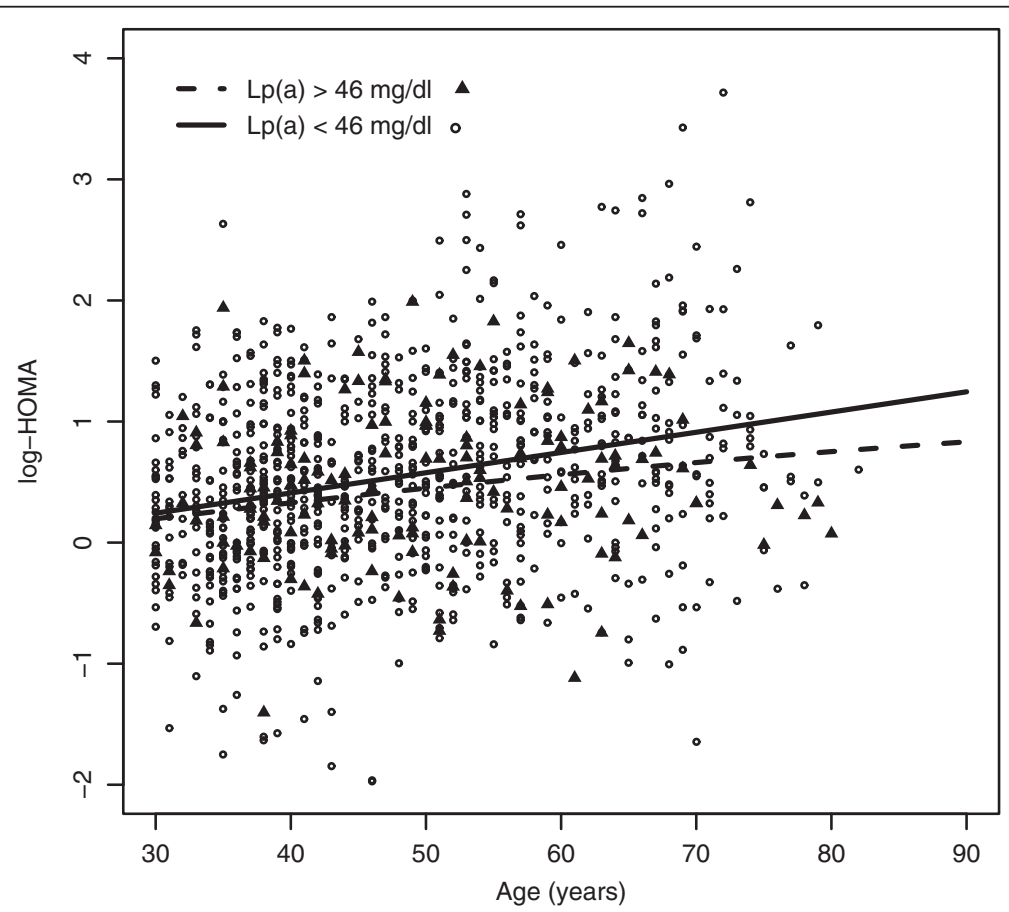

Figure 2 Parametric adjustment of HOMA-IR (log scale) for subjects with $L p(a)$ levels $>\mathbf{4 6} \mathrm{mg} / \mathrm{dl}$ and subjects with $\mathrm{Lp}(\mathrm{a})$ levels $\leq 46 \mathrm{mg} / \mathrm{dl}$. 
limit of the two-sided 95\% confidence interval for the difference between predicted values of log (HOMA-IR) was greater than 0 across all ages.

\section{Discussion}

The major finding in this population-based study was that after adjusting for established risk factors for diabetes (age, abdominal obesity, blood pressure, and serum levels of HDL cholesterol and triglycerides), the agerelated increase in the probability of having diabetes was significantly lower in subjects with higher levels of $L p(a)$.

This was a cross-sectional study, so no causal associations can be inferred from the results. In theory, either diabetes by itself or any accompanying condition could contribute to increase $\mathrm{Lp}(\mathrm{a})$ levels over the lifespan of each individual. However, it is well established that $\mathrm{Lp}$ (a) concentrations are not significantly affected by environmental factors. Instead, most of the variance in plasma $\mathrm{Lp}(\mathrm{a})$ is determined genetically. Alternatively, because both $L p(a)$ and diabetes increase the risk of cardiovascular disease, mortality rates may be increased at earlier ages in subjects with both risk factors. This would result in a greater proportion of individuals with low levels of $\mathrm{Lp}$ (a) among older survivors with diabetes. However, this possibility is inconsistent with recent data showing that, in contrast to what is observed in the general population, plasma $\mathrm{Lp}(\mathrm{a})$ levels are not significantly associated with cardiovascular risk in patients with diabetes [18]. Therefore, a more plausible explanation for our findings is that the age-related rate of progression to diabetes is slower in subjects with high levels of $\mathrm{Lp}(\mathrm{a})$. This interpretation is in accordance with the results of the WHS, a large prospective study involving more than 26,000 healthy middle-aged US women, which found that the cumulative probability of incident type 2 diabetes was inversely correlated with basal Lp(a) levels [11]. However, in contrast with the WHS and the CCHS, our study found a threshold effect for Lp(a). Specifically, the agerelated risk of diabetes was lower for subjects with $L p(a)$ levels above $46 \mathrm{mg} / \mathrm{dl}$.

We also observed that values of HOMA-IR, a surrogate marker of insulin resistance were lower in subjects with $\mathrm{Lp}$ (a) levels $>46 \mathrm{mg} / \mathrm{dl}$, suggesting that extremely high levels of $L p(a)$ are associated with less resistance to insulin. Some previous population-based studies failed to demonstrate any relationship between insulin sensitivity and $\mathrm{Lp}(\mathrm{a})$ levels [19]. However, in their seminal investigations in the 1970s, Dahlën \& Berg [20] found that, compared to controls with $\mathrm{Lp}$ (a) levels that were undetectable by agarose electrophoresis, older men with detectable $L p(a)$ levels showed higher levels of post-load blood glucose and lower levels of both fasting and postload insulin. More recently, using the euglycemic clamp technique, Haffner et al [21] observed a positive correlation between insulin sensitivity and Lp(a) levels in normoglycemic men. In a large sample of subjects in the San Antonio Family Heart Study, the same authors demonstrated that $\mathrm{Lp}(\mathrm{a})$ levels are inversely correlated with fasting insulin levels and with insulin and glucose concentrations measured 2 hours after an OGTT [22]. Finally, several studies have shown a positive correlation between Lp(a) and HDL cholesterol and a negative correlation between $\mathrm{Lp}(\mathrm{a})$ and triglycerides [23], indicating that $\mathrm{Lp}(\mathrm{a})$ shows an inverse relationship with the atherogenic dyslipidemia characteristically associated with insulin resistance. There is no obvious explanation for this inverse correlation between $\mathrm{Lp}(\mathrm{a})$ and both diabetes and insulin resistance. Because $\mathrm{Lp}(\mathrm{a})$ levels are determined mainly by genetic mechanisms, one possibility is that genetic polymorphisms associated with increased levels of $\mathrm{Lp}(\mathrm{a})$ are in linkage disequilibrium with gene(s) that protect against insulin resistance.

\section{Conclusions}

The present report suggests that the probability of having diabetes increases with age but that this increase is lower in subjects with serum levels of $L p(a)$ higher than $46 \mathrm{mg} / \mathrm{dl}$. Further studies are needed to clarify the nature of the interaction between $\operatorname{Lp}(\mathrm{a})$ and the risk of diabetes.

\section{Abbreviations}

CART: Classification and regression tree; CCHS: Copenhagen City Heart Study; HOMA-IR: Homeostasis Model Assessment for Insulin Resistance; Lp

(a): Lipoprotein(a); MAP: Mean arterial pressure; OGTT: Oral glucose tolerance test; WHS: Women's Health Study.

\section{Competing interests}

The authors declare that they have no competing interests.

\section{Author details}

${ }^{1}$ Section of Endocrinology and Nutrition, Hospital Universitario Insular, Avda. Marítima del Sur, s/n., 35016, Las Palmas de Gran Canaria, Spain.

${ }^{2}$ Department of Medical and Surgical Sciences, University of Las Palmas de Gran Canaria, Las Palmas de Gran Canaria, Spain. ${ }^{3}$ Department of

Mathematics, University of Las Palmas de Gran Canaria, Las Palmas de Gran Canaria, Spain.

\section{Authors' contributions}

M.B. conceived the study and wrote the manuscript, P.S. performed the statistical analyses, N.P.-M. M.J.L.-M. and C.R.-P. researched the data and helped to draft the manuscript, and F.J.N. reviewed the manuscript and contributed to the discussion. All authors read and approved the final manuscript.

Received: 16 April 2012 Accepted: 19 June 2012

Published: 2 July 2012

\section{References}

1. Nordestgaard BG, Chapman MJ, Ray K, Borén J, Andreotti F, Watts GF, Ginsberg H, Amarenco P, Catapano A, Descamps OS, Fisher E, Kovanen PT, Kuivenhoven JA, Lesnik P, Masana L, Reiner Z, Taskinen M-R, Tokgözoglu L, Tybjærg-Hansen A, for the European Atherosclerosis Society Consensus Panel: Lipoprotein(a) as a cardiovascular risk factor: current status. Eur Heart J 2010, 31:2844-2853. 
2. Boerwinkle E, Leffert CC, Lin J, Lackner C, Chiesa G, Hobbs HH: Apolipoprotein(a) gene accounts for greater than $90 \%$ of the variation in plasma lipoprotein(a) concentrations. J Clin Invest 1992, 90:52-60.

3. Kamstrup PR, Tybjaerg-Hansen A, Steffensen R, Nordestgaard BG: Genetically elevated lipoprotein(a) and increased risk of myocardial infarction. JAMA 2009, 301:2331-2339.

4. Li C, Ford ES, Tsai J, Zhao G, Balluz LS, Gidding SS: Serum non-high-density lipoprotein cholesterol concentration and risk of death from cardiovascular diseases among U.S. adults with diagnosed diabetes: the Third National Health and Nutrition Examination Survey linked mortality study. Cardiovasc Diabetol 2011, 10:46-57.

5. Herder C, Karakas M, Koenig W: Biomarkers for the prediction of type 2 diabetes and cardiovascular disease. Clin Pharmacol Ther 2011, 90:52-66.

6. Yoo HJ, Hwang SY, Hong HC, Choi HY, Yang SJ, Seo JA, Kim SG, Kim NH, Choi KM, Choi DS, Baik SH: Association of circulating omentin-1 level with arterial stiffness and carotid plaque in type 2 diabetes. Cardiovasc Diabetol 2011, 10:103-110.

7. Jenkins AJ, Steele JS, Janus ED, Santamaria JD, Best JD: Plasma apolipoprotein (a) is increased in Type 2 (non-insulin-dependent) diabetic patients with microalbuminuria. Diabetologia 1992, 35:1055-1059

8. Habib SS, Aslam M, Shah SFA, Naveed AK: Lipoprotein (a) is associated with basal insulin levels in patients with type 2 diabetes mellitus. Ara Bras Cardiol 2009, 93:25-30.

9. Haffner SM, Morales PA, Stern MP, Gruber KK: Lp(a) concentrations in NIDDM. Diabetes 1992, 41:1267-1272.

10. Rainwater DL, MacCluer JW, Stern MP, VandeBerg JL, Haffner SM: Effects of NIDDM on lipoprotein(a) concentration and apolipoprotein(a) size. Diabetes 1994, 43:942-946.

11. Mora S, Kamstrup PR, Rifai N, Nordestgaard BG, Buring JE, Ridker PM: Lipoprotein(a) and risk of type 2 diabetes. Clin Chem 2010, 56:1252-1260

12. Boronat M, Varillas VF, Saavedra P, Suárez V, Bosch E, Carrillo A, Nóvoa FJ: Diabetes mellitus and impaired glucose regulation in the Canary Islands (Spain): prevalence and associated factors in the adult population of Telde, Gran Canaria. Diabet Med 2006, 23:148-155.

13. World Health Organization: Definition, diagnosis and classification of diabetes mellitus and its complications. Report of a WHO Consultation, Part 1: Diagnosis and classification of Diabetes Mellitus. Geneva: World Health Organization; 1999:1-59.

14. Matthews DR, Hosker JP, Naylor BA, Treacher DF, Turner RC: Homeostasis model assessment: insulin resistance and $\beta$-cell function from fasting plasma glucose and insulin concentrations in man. Diabetologia 1985, 28:412-419.

15. Breiman L, Friedman JH, Olshen RA, Stone CJ: Classification and regression trees. Belmont, CA: Wadsworth International; 1984.

16. Grundy SM, Cleeman JI, Daniels SR, Donato KA, Eckel RH, Franklin BA, Gordon DJ, Krauss RM, Savage PJ, Smith SC Jr, Spertus JA, Costa F: Diagnosis and management of the metabolic syndrome: an American Heart Association/National Heart, Lung, and Blood Institute Scientific Statement. Circulation 2005, 112:2735-2752.

17. Park MY, Hastie T: Penalized logistic regression for detecting gene interactions. Biostatistics 2008, 9:30-50.

18. Qi Q, Workalemahu T, Zhang C, Hu FB, Qi L: Genetic variants, plasma lipoprotein(a) levels, and risk of cardiovascular morbidity and mortality among two prospective cohorts of type 2 diabetes. Eur Heart J 2012, 33:325-334.

19. Inoue K, Nago N, Matsuo H, Goto T, Miyamoto T, Saegusa T, Ishikawa S, Kario K, Nakamura Y, Igarashi M: Serum insulin and lipoprotein(a) concentrations. Diabetes Care 1997, 20:1242-1247.

20. Dahlën G, Berg K: Confirmation of an influence of the inherited Lp(a) variation on serum insulin and glucose levels. Clin Genet 1979, 16:418-427.

21. Haffner SM, Karhapaa P, Rainwater DL, Mykkanen L, Aldrete G Jr, Laakso M: Insulin sensitivity and $L p(a)$ concentrations in normoglycemic men. Diabetes Care 1995, 18:193-199.

22. Rainwater DL, Haffner SM: Insulin and 2-hour glucose levels are inversely related to $\mathrm{Lp}(\mathrm{a})$ concentrations controlled for LPA genotype. Arterioscler Thromb Vasc Biol 1998, 18:1335-1341.
23. Sharma S, Merchant J, Fleming SE: Lp(a)-cholesterol is associated with HDLcholesterol in overweight and obese African American children and is not an independent risk factor for CVD. Cardiovasc Diabetol 2012, 11:10-17.

doi:10.1186/1475-2840-11-81

Cite this article as: Boronat et al:: High levels of lipoprotein(a) are associated with a lower prevalence of diabetes with advancing age: Results of a cross-sectional epidemiological survey in Gran Canaria, Spain. Cardiovascular Diabetology 2012 11:81.

\section{Submit your next manuscript to BioMed Central and take full advantage of:}

- Convenient online submission

- Thorough peer review

- No space constraints or color figure charges

- Immediate publication on acceptance

- Inclusion in PubMed, CAS, Scopus and Google Scholar

- Research which is freely available for redistribution 